\title{
Article
}

\section{Course and impact of sleep disturbance in newly diagnosed epilepsy: A prospective registry study}

Xu, Ying, Hackett, Maree, Nikpour, Armin, Somerville, Ernest, Bleasel, Andrew, Ireland, Carol, Ghougassian, Daniel F., Anderson, Craig S. and Glozier, Nick

Available at http://clok.uclan.ac.uk/33446/

Xu, Ying, Hackett, Maree ORCID: 0000-0003-1211-9087, Nikpour, Armin, Somerville, Ernest, Bleasel, Andrew, Ireland, Carol, Ghougassian, Daniel F., Anderson, Craig S. and Glozier, Nick (2020) Course and impact of sleep disturbance in newly diagnosed epilepsy: A prospective registry study. Clinical Neurology and Neurosurgery . p. 105963. ISSN 0303-8467

It is advisable to refer to the publisher's version if you intend to cite from the work. http://dx.doi.org/10.1016/j.clineuro.2020.105963

For more information about UCLan's research in this area go to

http://www.uclan.ac.uk/researchgroups/ and search for < name of research Group>.

For information about Research generally at UCLan please go to http://www.uclan.ac.uk/research/

All outputs in CLoK are protected by Intellectual Property Rights law, including Copyright law. Copyright, IPR and Moral Rights for the works on this site are retained by the individual authors and/or other copyright owners. Terms and conditions for use of this material are defined in the policies page.

\section{CLoK}

Central Lancashire online Knowledge www.clok.uclan.ac.uk

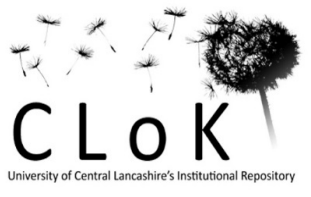




\section{Abstract}

Objective: To determine the course of sleep distrurbance (insomnia symptoms and short sleep duration) after a diagnosis of epilepsy and their associations with seizure control, mood, disability, and quality of life.

Patients and Methods: One hundred and sixty-nine adults were drawn from the Sydney Epilepsy Incidence Study to Measure Illness Consequences (SEISMIC), a prospective, multicenter, community-wide study in Sydney, Australia. Sociodemographic, psychosocial, clinical characteristics, and information on sleep disturbance were obtained early (median 48 [IQR15-113] days) after a diagnosis of epilepsy, and at 12 months. Logistic regression models were used to determine associations between patterns of sleep disturbance with outcomes at 12 months.

Results: Insomnia symptoms and/or short sleep duration were present in $18-23 \%$ of participants at both time points, with over half (54-61\%) showing a chronic pattern. There was no association of sleep disturbance pattern with recurrent seizures, medication use or disability. Chronic insomnia symptoms and short sleep duration were strongly associated with worse mental health (aOR 3.76, 95\% Cl 1.28-11.06; and aOR $5.41,95 \% \mathrm{Cl} 1.86-15.79)$ and poorer quality of life at 12 months (aOR $3.02,95 \%$ $\mathrm{Cl} 1.03-8.84$; and aOR 3.11, 95\% Cl 1.10-8.82), after adjusting for clinical features of epilepsy and comorbidity. Those whose sleep disturbance remitted had no adverse outcomes.

Conclusions: Insomnia symptoms and short sleep duration are less common in people with recently-diagnosed than chronic epilepsy. The temporal association with poor psycholosocial outcomes supports specific interventions addressing sleep disturbance. 
Keywords: epilepsy, sleeping, public health, epidemiology 


\section{Introduction}

Adults with epilepsy show significantly more sleep-related disturbance than the general population [1]. Insomnia, defined variously, affects between one quarter and one half $[2,3]$ of adults with epilepsy, with one third sleeping six or fewer hours per night according to the 2010 National Health Interview Survey of USA [4]. Epilepsy can disrupt sleep, and some possible mechanisms include alterations in neuronal synchronizational activity [5] and thalamocortical/corticothalamic networks [6] and medication-related effects [7]. An example of this relationship is the improvement in subjective daytime sleepiness and sleep quality that patients with drug-resistant temporal lobe epilepsy experience after epilepsy surgery [8]. Conversely, sleep deprivation has long been recognized as lowering seizure thresholds [9], while improved seizure control has been noted in those who have been successfully treated for co-occurring sleep apnea [10]. Sleep disorders are associated with anxiety and depression, suicidal ideation and reduced quality of life in adults with epilepsy $[11,12]$. Sleep problems occur early after a diagnosis of epilepsy. Recently diagnosed patients display greater sleep instability and fragmentation than those whose epilepsy was diagnosed several years previously [13]. However, most studies of this topic have been cross sectional, with consequent selection and information biases, and limitations over causal inference. We analyzed data from the Sydney Epilepsy Incidence Study to Measure Illness Consequences (SEISMIC) to determine the course of insomnia symptoms and short sleep duration in adults with a new diagnosis of epilepsy, and whether these variables were associated with seizure control, anxiety or depression, disability and quality of life.

\section{Patients and Methods}

\subsection{Study design and patient}


SEISMIC is registered on the Australia New Zealand Clinical Trial Registration database, and the protocol and main results are published [14-17]. In brief, people of all ages with a new diagnosis of epilepsy were identified and enrolled through a geographically based multi-site ascertainment process in Sydney, Australia from July 2008 to December 2013. Epilepsy was defined as 2 or more unprovoked seizures, defined according to the International League Against Epilepsy (ILAE) Commission on Epidemiology and Prognosis as "a transient occurrence of signs or symptoms due to abnormal excessive or synchronous neuronal activity in the brain." Only adult participants (i.e. $\geq 18$ years) are included in the current analyses.

\section{2 "A new diagnosis of epilepsy" case ascertainment and confirmation}

A surveillance system was established across hospitals in Sydney: Bankstown Hospital, Prince of Wales Hospital, Royal Prince Alfred Hospital, St. Vincent's Hospital, Sydney Children's Hospital at Randwick, Westmead Hospital including Westmead Children's Hospital, Concord Repatriation General Hospital, and Canterbury Hospital. This approach involved regular review of the records of all patients who presented to any of those hospital areas: neurology outpatient clinics and departments, EEG labs, Centre of the University of Sydney, referrals from private consulting rooms of epileptologists, neurologists, pediatricians, and general practitioners, and cases referred directly from Epilepsy Action Australia, a not-for-profit nongovernment organization, were also reviewed. A lead clinician at each referral site, principal investigators, maintained a screening log of all potentially eligible patients and documented when consent was obtained. Clinical information required to determine "a new diagnosis of epilepsy" of consented participants were abstracted from medical notes, reviewed by a Diagnostic Committee, and validated against ILAE guidelines [18].

\subsection{Assessments}


Trained research nurses then undertook in-person structured interviews with participants within 28 days of, or as soon as possible after, their diagnosis (baseline), and 12 months later. Each interview included clinical and age-specific psychosocial assessments [14, 15].

\subsection{Sleep disturbance measures}

Insomnia symptoms and short sleep duration were ascertained using the Pittsburgh Sleep Quality Index (PSQI) [19], which has been validated in adults with epilepsy, and shows similar relations to demographic and clinical characteristics as other common scales, such as the Insomnia Severity Index [3] and the Epworth Sleepiness Scale [8]. Insomnia symptoms were ascertained using two items, rated on a 4-point frequency scale: "During the past month, how often have you had trouble sleeping because" (1) "you cannot get to sleep within 30 minutes?" and (2) "you wake up in the middle of the night or early morning?". Overall sleep quality was assessed using the final question "During the past month, how would you rate your sleep quality overall?" rated on a 4point scale ("very good" to "very bad"). The combination of responses of "three or more times a week" to (1) and/or (2), plus "fairly bad" or "very bad" overall sleep quality, were defined as "insomnia symptoms". An "insomnia symptoms course" variable was created as: (1) "chronic", insomnia symptoms present at baseline and 12 months; (2) "recovery", insomnia symptoms present at baseline but not at 12 months; (3) "late", insomnia symptoms first present at 12 months; and (4) "never", no insomnia symptoms at either baseline or 12 months.

Sleep duration was ascertained from the single question "During the past month, on average, how many hours of actual sleep did you get at night?". Short sleep duration was defined as less than the National Sleep Foundation (NSF)'s minimum recommended duration of $<7$ hours [20]. This NSF's recommendation was adopted 
by Australian Sleep Health Foundation. A "short sleep duration course" variable (i.e. chronic, recovery, late and never) was created as above.

\subsection{Other measures}

Information collected included demographic and socioeconomic characteristics, psychosocial factors, history of other physical disorders, etiology and clinical pattern of seizures, use of antiepileptic drugs (AEDs), and family history of epilepsy. Participants whose baseline assessments were undertaken beyond the initial 28-day period, were asked to recall their situation within the first month of diagnosis, except for the information on "current" use of AEDs. Economic hardship was defined as either a household's inability to make a necessary household payment or the demonstration of dissaving behavior, compising 16 items from financial strain questions of the Australian Bureau of Statistics Household Expenditure Survey [21]. Family function was assessed with the Family Adaptation, Partnership, Growth, Affection and Resolve (APGAR) questionnaire [22]. Alcohol consumption was assessed using the World Health Organization's Alcohol Use Disorders Identification Test (WHO-AUDIT-c) [14, 23]. Perceived job stress was determined using a short form of the Job Content Questionnaire (JCQ) [24]. Job strain was defined as combination of high demands and low control. Prior treatment for mood disorders includes history of taking antidepressants, sleeping tablets, medication for anxiety/anxiolytics/benzodiazepines or major tranquilizers and psychotherapy. Perceived stigma was determined by a single question of whether the participant thought that other people were uncomfortable, treated him/her differently, or preferred to avoid him/her. Co-morbidity included self-reported cardiovascular, respiratory, ophthalmology, otorhinolaryngology, gastrointestinal, hepatic, renal, genito-urinary, musculoskeletal and endocrine- 
metabolic diseases, but not including neurological (e.g. epilepsy) and psychiatric/behavioral conditions.

\subsection{Outcome measures}

Seizure control was assessed at 12 months by a single question about the presence/absence of seizures in the past eight months. Anxiety and depression were measured using the Hospital Anxiety and Depression Scale (HADS) subscales,[25] which contain 7 items on a 4 -point scale. A score of $\geq 8$ on these subscales indicates anxiety or depression, respectively. Disability was measured using the 12-item World Health Organization`s Disability Assessment Schedule (WHODAS, http://www.who.int/classifications/icf/whodasii/en/), with higher scores indicating more disability; the measure was dichotomized at the median as high $(\geq 2)$ and low $(\leq 1)$ disability. Quality of life was measured on the EuroQol Group 5-Dimension selfreported questionnaire (EQ-5D), including the 11-point visual analogue scale (VAS) where scores of 10 and 0 indicate the "best possible" and "worst possible" (i.e. as bad as or worse than being dead) quality of life, respectively. Participants, with lower than the median EQ-5D score (cut point at $<1$ ) or a global rating of quality of life $(\leq 7)$, were categorized as the group with poorer quality of life.

\subsection{Analysis}

We assessed the potential for selection bias by comparing those with and without full sleep or follow-up data, and for information bias by comparing the samples according to time of baseline assessment ( $\leq$ versus $>28$ days). In complete-case analyses, Kruskal-Wallis and chi-squared tests were used to estimate associations of baseline sleep disturbance with socio-demographic, psychosocial, clinical and epilepsy-related characteristics. 
The point frequency at baseline and 12 months, and the pattern of insomnia symptoms and short sleep duration over these two assessments, were calculated. The insomnia symptoms or short sleep duration course variable was used as the "exposure" in the models. Logistic regression models were used to determine associations of the course, with 12 months outcomes: presence/absence of seizures in the past eight months, presence/absence of anxiety or depression, disability, and quality of life. Models were first adjusted for age (continuous) and sex (model I), then sequentially for on/off antiepileptic medication at 12 months, and presence/absence of ongoing seizures in the past 8 months at 12 months assessment (not applicable for the outcome of seizure control) (model II); and then sequentially for history of treatment for mood disorders before the first seizure and history of co-morbidities at the diagnosis of epilepsy (model III). Data are reported with odds ratios (OR) and 95\% confidence intervals (CI). All analyses were performed using SAS version 7.1 (SAS institute, Cary, NC, USA).

\section{Results}

There were 259 eligible adults with a new diagnosis of epilepsy, but 90 (35\%) were excluded due to loss of follow-up or invalid sleep assessment at baseline and/or 12 months. Thus, $169(65 \%)$ remained in the study group (median [interquartile range, IQR] age 42 [28-58] years, 55\% male; Table e-1). All participants self-completed the clinical and psychosocial assessments but with a nominated proxy present in $15(9 \%)$ at baseline and $8(5 \%)$ at 12 months. Sixty-four percent of the study group had baseline interviews conducted beyond 28 days post-diagnosis (median [IQR] 48 [15113] days).

Compared to those participants who were lost to follow-up or had incomplete or missing PSQI data, the study group were less likely to be current full- or part-time 
students $(P=0.03)$, or experience economic hardship $(P=0.003)$, and were more likely to be in paid work $(P=0.05)$ and have an annual household income $\geq A u s \$ 100,400$ $(P=0.02)$. The study group were also more likely to have seizures during sleep or napping ( $P=0.03$ ), and to have waited for $\geq 8$ weeks for a specialist neurologist review $(P=0.001)$. Participants interviewed beyond 28 days, reported more perceived stigma $(P=0.03)$ within the first month of diagnosis and more $A E D$ use $(P=0.002)$, specifically levetiracetam $(P=0.006)$, at the time of baseline interview, than those assessed earlier (Table e-2).

\subsection{Cross sectional association of insomnia symptoms and short sleep duration}

Insomnia symptoms was present in 33 participants (20\%) at baseline, and 31 participants (18\%) at 12 months; while 39 participants $(23 \%)$ at baseline and 38 participants (22\%) at 12 months reported a short sleep duration of $\leq 6$ hours. Insomnia symptoms at baseline was associated with treatment for mood disorders before seizures onset $(P=0.04)$, co-morbidity $(P=0.01)$ and use of levetiracetam $(P=0.03)$, and a lower likelihood of seizures during naps $(p=0.04)$, but no other demographic or clinical features. Of the characteristics assessed only older participants $(P=0.01)$ and those who owned accommodation $(P=0.02)$ were more likely to report short sleep duration at baseline.

\subsection{Prospective pattern of insomnia symptoms and short sleep duration}

Fourteen participants (8\%) with insomnia symptoms at baseline had recovered at 12 months (recovery); 12 participants (7\%) had new onset of insomnia symptoms at 12 months (late); and 19 participants (11\%) reported insomnia symptoms at both time points (chronic). For short sleep duration, 18 participants (11\%) were in recovery, and 
$17(10 \%)$ and $21(12 \%)$ were in late and chronic stages, respectively (Table 2 and Table e-3).

\subsection{Association of course of insomnia symptoms and short sleep duration and outcome}

There was no consistent association of the pattern of either insomnia symptoms or short sleep duration with the later presence of seizures or disability (Table 2). There was a trend for those whose insomnia symptoms had recovered to be more likely to have ongoing seizures (adjusted odds ratio [aOR] 4.34, 95\% $\mathrm{Cl} 1.31$ to 14.44), and those who had late onset insomnia symptoms to have greater disability (aOR 4.20, 95\% Cl 1.08 to 14.42), although these associations attenuated after adjustment for medication use. Those with chronic short sleep duration were more likely to have ongoing seizures (aOR $3.58,95 \% \mathrm{Cl} 1.16$ to 10.99) after adjustment for age, sex and medication use, but this attenuated after adjustment for physical and psychological comorbidity.

Chronic insomnia symptoms and short sleep were strongly associated with worse mental health (aOR $3.76,95 \% \mathrm{Cl} 1.28$ to 11.06 ; and aOR $5.41,95 \% \mathrm{Cl} 1.86$ to 15.79 ) and poorer quality of life at 12 months $(\mathrm{aOR} 3.02,95 \% \mathrm{Cl} 1.03$ to 8.84 ; and aOR 3.11 , $95 \% \mathrm{Cl} 1.10$ to 8.82 ), after adjusting for clinical features of epilepsy and physical and psychological comorbidity. New onset insomnia symptoms, but not new onset short sleep duration, showed a similar association.

\section{Discussion}

This prospective community-based study has shown that the problems of insomnia symptoms and short sleep duration are as common in people soon after a diagnosis of epilepsy as in the community, but no more so. The frequency of insomnia symptoms (20\% at baseline, $18 \%$ at 12 months) in our sample fell within the range of reported 
difficulty getting to sleep or staying asleep in adult Australian surveys [26, 27], but was considerably lower than that reported in cross-sectional clinic-based studies of adults with established epilepsy $(29 \%$ to $74 \%$, the wide range of reported point prevalence being notable itself) [28]. Approximately one-fifth of our participants reported sleeping fewer than seven hours, which is much higher than that reported $(5 \%)$ in the Australian population [29], but lower than that reported (34\% [4] and 39\% [1]) in adults with epilepsy in clinical studies. These discrepancies might reflect the varying definitions and methods of assessing insomnia and short sleep duration, and in differences in the case-mix of study populations, e.g. our study group was newly diagnosed who are different to chronic clinical smaples. For instance only a small proportion $(n=12)$ of the sample required polytherapy, when polytherapy has been consistently associated with insomnia [3, 30].

People with generalized onset seizures were initally reported to have more frequent sleep abnormalities than those with focal seizures [13], but our data confirmed findings from a Greek study [2], that there was no association between focal or generalized seizure patterns with insomnia or short sleep duration. In contrast to the previously reported association between nocturnal seizures and insomnia [31], our data showed an association between nocturnal seizures and the absence of insomnia symptoms.

Half of this study group were not taking any anti-epileptic medication, which is consistent with the reported $37 \%$ of individuals with newly diagnosed epilepsy remained untreated up to 3 years after diagnosis [32]. There was no association of AED use with sleep disturbance over time (Table e-4), but levetiracetam, a secondgeneration AED, was associated with insomnia symptoms at baseline in our study. Levetiracetam has been associated with subclinical depression,[33] and the overlap with depression and sleep disturbances is well defined. Although some reports 
suggest fewer sleep problems than an older AED (carbamazepine) [11, 34], and improvement in both subjective parameters of sleep continuity and objective sleep efficiency (percentage of the time asleep/time in bed) in patients with epilepsy [35, 36], in a randomised trial participants with newly diagnosed epilepsy taking levetiracetam were 2.5 times more likely to report insomnia compared with their counterparts taking controlled-release carbamazepine, when used as the first treatment [37]. This may reflect confounding by indication as clinicians might be prescribing levetiracetam because of baseline sleep problems in this study, although there are opposite evidence. Insomnia ranked the $37^{\text {th }}$ in decreasing order of adverse events frequency when levetiracetam (compared to placebo) was added onto usual AED care in treating drugresistant focal epilepsy [38], and was similarly uncommon among those with generalized seizures [39]. Further, when not used as an add-on treatment, levetiracetam was associated with lower odds of insomnia among veterans with epilepsy [40]. Valproic acid, often considered a "sedating" AED [40], was not associated with absence of insomnia symptoms in our study, although the numbers of patients on individual AEDs were small, and the assessement of AEDs is complicated by variable dose, duration, and interactions with other AEDs (although few participants required polytherapy).

While there was no consistent association of the pattern of insomnia symptoms or short sleep duration with later seizure control or disability, chronic insomnia symptoms, short sleep, and new onset insomnia symptoms, were strongly associated with worse mental health and poorer quality of life at 12 months. Unlike commonly held clinical views we did not find any propsective association between insomnia symptoms or short sleep duration with later seizure control. This may be due to the small sample size, as there was a trends towards those whose early insomnia symptoms who later recovered, and 
those who had chronic short sleep duration, being more likely to have ongoing seizures (all $\mathrm{P}<0.1)$. In adults with epilepsy, there are established cross-sectional associations between insomnia [2] or night awakenings [41] and more frequent seizures, and also for the occurrence of subjective daytime sleepiness and poor sleep quality in patients with drug-resistant temporal lobe epilepsy who later improve after a significant seizure reduction post-surgery [8]. In addition, there was no statistical association of patterns of insomnia symptoms or short sleep duration with WHODAS-measured global disability. The relativley large OR for chronic insomnia symptoms and disability, was hampered by sample size, but is a similar effect size to that seen for the impact of chronic insomnia on disability post stroke[42].

Cross-sectional associations between insomnia and anxiety or depression have been recognized in epilepsy $[3,11,30,40,43]$. This is the first time this has been shown prospectively in epilepsy but insomnia consistently predicts future depression in gerneral population studies [44]. Cross-sectional and prospective associations between short sleep duration and depressive symptoms have been shown in an urban multi-ethnic cohort of older adults [45]. These associations were independent of previous diagnoses of depression but may still reflect a single underlying condition, which is supported by the stronger association with "late" insomnia symptoms. Conversely, chronic short sleep duration is more strongly associated with poor mental health than late short sleep duration, and thus is more likely to represent a risk factor.

Consistent with the widely reported cross-sectional associations between insomnia [2, $3,43]$, or sleep quality $[1,3,46]$ with quality of life in adults with epilepsy, our data have shown detrimental associations of insomnia symptoms or short sleep duration with EQ$5 \mathrm{D}$ and VAS measures of quality of life. There is additional cross-sectional evidence that EQ-5D index and VAS scores declined with deterioration of sleep quality, abeit not 
with short sleep duration, among older Chinese ( $\geq 60$ years), after adjusting sociodemographic factors, health conditions and lifestyle habits [47]. We note that although an association between insomnia symptoms or short sleep duration and VAS measured quality of life existed, even after adjusting history of treatment for mood disorders before the first seizure, there may be mediating effects of later onset depression, between sleep quality or short sleep duration and self-reported life satisfaction [48].

Strengths of our study include the relatively large group of adults, recruited as early as possible after a diagnosis of epilepsy from multiple community and hospital locations in a defined population, and the focus on insomnia symptoms and short sleep duration as primary "exposure", rather than general sleep complaints and quality without clear descriptions [1, 49], or a single item assessing poor sleep [41, 50]. We acknowledge, however, that attrition to the clinical cohort may have led to selection bias, while potential recall bias could have influenced the data among those participants who completed their baseline interviews more than 28 days after the diagnosis. The "insomnia symptoms" were not adjudicated against standard measures as assessed by clinicians, and are only a proxy for Diagnostic and Statistical Manual of Mental Disorders (DSM-5) insomnia disorder 307.42 (F51.01)". Also, the term "chronic" used in this study should be differentiated from a "chronic insomnia" diagnosis. We do not have information on sleep disturbance between two assessments, whereas the International Classification of Sleep Disorder (ICSD-3) duration criterion for chronic insomnia disorder is 3 months. We acknowledge the lack of objective measurement of sleep duration, although the NSF's recommendation does not rely on laboratory measured sleep time [20]. Furthermore, although Australians who experience insomnia and sleep fewer than seven hours have the highest risk of chronic mental 
health problems [51], our sample was too small to allow a reliable assessment of the co-existence of insomnia symptoms and short sleep duration, and even to allow indepth analyses of the impact of dynamic insomnia symptoms or short sleep duration courses on outcomes, especially when adjusted for confounders. "Presence/absence of any seizure in the last past 8 month" cannot wholly represent the sophisticated seizure burden along with other crucial factors (e.g. seizure frequency, seizure type, and epilepsy syndromes) that may underpin the association. Finally, we note the possibility for type I error due to multiple testing.

In summary, our study has shown that one in five adults with a recent diagnosis of epilepsy have insomnia symptoms and/or short sleep duration, and in half, these become chronic problems over the subsequent 12 months. Being statistically underpowered may have precluded detection of a relation between habitual sleep disturbance and presence of going seizures or disability. However, there was a strong association between insomnia symptoms and short sleep duration and psychological wellbeing. Importantly, although there were cross sectional associations of insomnia symptoms and short sleep duration with poor mental health and quality of life, those whose sleep improved also demonstrated no long term adverse psychosocial sequelae, providing a strong rationale for testing the effectiveness of sleep interventions in people with newly diagnosed epilepsy. 


\section{Acknowledgments}

The authors acknowledge the dedication and effort of the research nurses, doctors, nurses and administration staff associated with the study; and of course the support of participants and their families and friends.

During the completion of this work, Ying Xu held a University of Sydney Postgraduate Award, Maree Hackett a National Heart Foundation Future Leader Fellowship (20142017, 100034) and an NHMRC Career Development Fellowship (2018-2021, APP1141328), and Craig Anderson an NHMRC Senior Principal Research Fellowship.

\section{Funding}

This study was supported by National Health and Medical Research Council (NHMRC) of Australia Partnership Grant 571448 and Australian Research Council (ARC) Discovery Grant DP1096655. Funding partners included Epilepsy Action Australia, the Epilepsy Society of Australia, the Sydney South West Area Health Service New South Wales, and The George Institute for Global Health.

\section{Declaration of interest statement}

The authors report no disclosures. 


\section{References}

1. de Weerd A, de Haas S, Otte A, Trenite DK, van Erp G, Cohen A, de Kam M, van Gerven J. Subjective sleep disturbance in patients with partial epilepsy: a questionnaire-based study on prevalence and impact on quality of life. Epilepsia 2004, 45(11):1397-1404. doi:10.1111/j.0013-9580.2004.46703.x

2. Piperidou C, Karlovasitou A, Triantafyllou N, Terzoudi A, Constantinidis T, Vadikolias K, Heliopoulos I, Vassilopoulos D, Balogiannis S. Influence of sleep disturbance on quality of life of patients with epilepsy. Seizure 2008, 17(7):588-594. doi:10.1016/j.seizure.2008.02.005

3. Vendrame M, Yang B, Jackson S, Auerbach SH. Insomnia and epilepsy: a questionnaire-based study. Journal of Clinical Sleep Medicine 2013, 9(2):141146. doi:10.5664/jcsm.2410

4. Cui W, Zack MM, Kobau R, Helmers SL. Health behaviors among people with epilepsy--results from the 2010 National Health Interview Survey. Epilepsy and Behavior 2015, 44:121-126. doi:10.1016/j.yebeh.2015.01.011

5. Sinha SR. Basic mechanisms of sleep and epilepsy. Journal of Clinical Neurophysiology 2011, 28(2):103-110. doi:10.1097/WNP.0b013e3182120d41

6. Bagshaw AP, Rollings DT, Khalsa S, Cavanna AE. Multimodal neuroimaging investigations of alterations to consciousness: the relationship between absence epilepsy and sleep. Epilepsy and Behavior 2014, 30:33-37. doi:10.1016/j.yebeh.2013.09.027

7. Jain SV, Glauser TA. Effects of epilepsy treatments on sleep architecture and daytime sleepiness: an evidence-based review of objective sleep metrics. Epilepsia 2014, 55(1):26-37. doi:10.1111/epi.12478

8. Carrion MJM, Nunes ML, Martinez JVL, Portuguez MW, da Costa JC. Evaluation of sleep quality in patients with refractory seizures who undergo epilepsy surgery. Epilepsy and Behavior 2010, 17(1):120-123. doi:10.1016/j.yebeh.2009.11.008

9. Accardo JA, Malow BA. Sleep, epilepsy, and autism. Epilepsy and Behavior 2015, 47:202-206. doi:10.1016/j.yebeh.2014.09.081

10. Devinsky O, Ehrenberg B, Barthlen GM, Abramson HS, Luciano D. Epilepsy and sleep apnea syndrome. Neurology 1994, 44(11):2060-2064. doi:10.1212/WNL.44.11.2060

11. Xu X, Brandenburg NA, McDermott AM, Bazil CW. Sleep disturbances reported by refractory partial-onset epilepsy patients receiving polytherapy. Epilepsia 2006, 47(7):1176-1183. doi:10.1111/j.1528-1167.2006.00591.x

12. Wigg CM, Filgueiras A, Gomes Mda M. The relationship between sleep quality, depression, and anxiety in patients with epilepsy and suicidal ideation. Arquivos de Neuro-Psiquiatria 2014, 72(5):344-348. doi:10.1590/0004$282 \times 20140017$

13. Mendez M, Radtke RA. Interactions between sleep and epilepsy. Journal of Clinical Neurophysiology 2001, 18(2):106-127. doi:10.1097/00004691200103000-00003 
14. Hackett ML, Glozier NS, Martiniuk AL, Jan S, Anderson CS. Sydney epilepsy incidence study to measure illness consequences: the SESIMIC observational epilepsy study protocol. BMC neurology 2011, 11:3. doi:10.1186/1471-237711-3

15. Xu Y, Hackett ML, Glozier N, Nikpour A, Bleasel A, Somerville E, Lawson J, Jan $S$, Hyde L, Todd $L$ et al. Frequency and predictors of psychological distress after a diagnosis of epilepsy: a community-based study. Epilepsy and Behavior 2017, 75:190-195. doi:10.1016/j.yebeh.2017.07.044

16. Xu Y, Hackett ML, Glozier N, Nikpour A, Somerville E, Bleasel A, Ireland C, Anderson CS. Return to driving after a diagnosis of epilepsy: a prospective registry study. Epilepsia 2018, 59(3):661-667. doi:10.1111/epi.14001

17. Xu Y, Neuen DR, Glozier N, Nikpour A, Somerville E, Bleasel A, Ireland C, Anderson CS, Hackett ML. Disability patterns over the first year after a diagnosis of epilepsy. Clinical Neurology and Neurosurgery 2019, 179:60-65. doi:10.1016/j.clineuro.2019.02.022

18. Berg AT, Berkovic SF, Brodie MJ, Buchhalter J, Cross JH, van Emde Boas W, Engel J, French J, Glauser TA, Mathern GW et al. Revised terminology and concepts for organization of seizures and epilepsies: report of the ILAE Commission on Classification and Terminology, 2005-2009. Epilepsia 2010, 51(4):676-685. doi:10.1111/j.1528-1167.2010.02522.x

19. Buysse DJ, Reynolds CF, Monk TH, Berman SR, Kupfer DJ. THE The Pittsburgh sleep quality index - a new instrument for psychiatric practice and research. Psychiatry Research 1989, 28(2):193-213. doi:10.1016/01651781(89)90047-4

20. Watson NF, Badr MS, Belenky G, Bliwise DL, Buxton OM, Buysse D, Dinges DF, Gangwisch J, Grandner MA, Kushida C et al. Recommended amount of sleep for a healthy adult: a joint consensus statement of the American Academy of Sleep Medicine and Sleep Research Society. Sleep 2015, 38(6):843-844. doi:10.5665/sleep.4716

21. Department of Family and Community Services (2001). Hardship in Australia an analysis of financial stress indicators in the 1998-99 Australian Bureau of Statistics Household Expenditure Survey.

22. Smilkstein G. The family APGAR: a proposal for a family function test and its use by physicians. Journal of Family Practice 1978, 6(6):1231-1239.

23. Bush K, Kivlahan DR, McDonell MB, Fihn SD, Bradley KA. The AUDIT alcohol consumption questions (AUDIT-C): an effective brief screening test for problem drinking. Ambulatory Care Quality Improvement Project (ACQUIP). Alcohol Use Disorders Identification Test. Archives of Internal Medicine 1998, 158(16):1789-1795. doi:10.1001/archinte.158.16.1789

24. Karasek R, Brisson C, Kawakami N, Houtman I, Bongers P, Amick B. The Job Content Questionnaire (JCQ): an instrument for internationally comparative assessments of psychosocial job characteristics. Journal of Occupational Health Psychology 1998, 3(4):322-355. doi: 10.1037//1076-8998.3.4.322

25. Zigmond AS, Snaith RP. The hospital anxiety and depression scale. Acta psychiatrica Scandinavica 1983, 67(6):361-370. 
26. Mansfield DR, Hillman DR, Antic NA, McEvoy RD, Rajaratnam SMW. Sleep loss and sleep disorders. Medical Journal of Australia 2013, 199(8):S5-S6. doi:10.5694/mja13.11157

27. Cunnington D, Junge MF, Fernando AT: Insomnia. Prevalence, consequences and effective treatment. Medical Journal of Australia 2013, 199(8):S36-S40. doi:10.5694/mja13.10718

28. Macedo P, Oliveira PS, Foldvary-Schaefer N, Gomes MDM. Insomnia in people with epilepsy: A review of insomnia prevalence, risk factors and associations with epilepsy-related factors. Epilepsy Research 2017, 135:158167. doi:10.1016/j.eplepsyres.2017.05.014

29. Bin YS, Marshall NS, Glozier N. Sleeping at the limits: the changing prevalence of short and long sleep durations in 10 countries. American Journal of Epidemiology 2013, 177(8):826-833. doi:10.1093/aje/kws308

30. Yang KI, Grigg-Damberger M, Andrews N, O'Rourke C, Bena J, FoldvarySchaefer N. Severity of self-reported insomnia in adults with epilepsy is related to comorbid medical disorders and depressive symptoms. Epilepsy and Behavior 2016, 60:27-32. doi:10.1016/j.yebeh.2016.03.023

31. Ismayilova V, Demir AU, Tezer FI. Subjective sleep disturbance in epilepsy patients at an outpatient clinic: a questionnaire-based study on prevalence. Epilepsy Research, 115:119-125. doi:10.1016/j.eplepsyres.2015.06.009

32. Hogan RE. Delay of treatment, after diagnosis, as a contributor to the "treatment gap" in epilepsy. Epilepsy Currents 2019, 19(6):385-386. doi:10.1177/1535759719874793

33. Joshi R, Tripathi M, Gupta P, Goyal A, Gupta YK. Depression in patients receiving pharmacotherapy for epilepsy: an audit in a tertiary care centre. Pharmacological Reports, 71(5):848-854. doi: 0.1016/j.pharep.2019.04.021

34. van Golde EG, Gutter T, de Weerd AW. Sleep disturbances in people with epilepsy; prevalence, impact and treatment. Sleep Medicine Reviews 2011, 15(6):357-368. doi:10.1016/j.smrv.2011.01.002

35. Bell C, Vanderlinden H, Hiersemenzel R, Otoul C, Nutt D, Wilson S. The effects of levetiracetam on objective and subjective sleep parameters in healthy volunteers and patients with partial epilepsy. Journal of Sleep Research 2002, 11(3):255-263. doi:10.1046/j.1365-2869.2002.00301.x

36. Cho YW, Kim DH, Motamedi GK. The effect of levetiracetam monotherapy on subjective sleep quality and objective sleep parameters in patients with epilepsy: compared with the effect of carbamazepine-CR monotherapy. Seizure 2011, 20(4):336-339. doi:10.1016/j.seizure.2011.01.006

37. Brodie MJ, Perucca E, Ryvlin P, Ben-Menachem E, Meencke HJ. Comparison of levetiracetam and controlled-release carbamazepine in newly diagnosed epilepsy. Neurology 2007, 68(6):402-408. doi:10.1212/01.wnl.0000252941.50833.4a

38. Mbizvo GK, Dixon P, Hutton JL, Marson AG. The adverse effects profile of levetiracetam in epilepsy: a more detailed look. International Journal of Neuroscience 2014, 124(9):627-634. doi:10.3109/00207454.2013.866951 
39. Delanty N, Jones J, Tonner F. Adjunctive levetiracetam in children, adolescents, and adults with primary generalized seizures: open-label, noncomparative, multicenter, long-term follow-up study. Epilepsia 2012, 53(1):111-119. doi:10.1111/j.1528-1167.2011.03300.x

40. Lopez MR, Cheng JY, Kanner AM, Carvalho DZ, Diamond JA, Wallace DM. Insomnia symptoms in South Florida military veterans with epilepsy. Epilepsy and Behavior 2013, 27(1):159-164. doi:10.1016/j.yebeh.2013.01.008

41. Hoeppner JB, Garron DC, Cartwright RD. Self-reported sleep disorder symptoms in epilepsy. Epilepsia 1984, 25(4):434-437. doi:10.1111/j.15281157.1984.tb03439.x

42. Glozier N, Moullaali TJ, Sivertsen B, Kim D, Mead G, Jan S, Li Q, Hackett ML. The course and impact of poststroke insomnia in stroke survivors aged 18 to 65 years: results from the Psychosocial Outcomes In StrokE Cerebrovascular Diseases Extra 2017, 7(1):9-20. doi:10.1159/000455751

43. Quigg M, Gharai S, Ruland J, Schroeder C, Hodges M, Ingersoll KS, Thorndike FP, Yan G, Ritterband LM. Insomnia in epilepsy is associated with continuing seizures and worse quality of life. Epilepsy Research 2016, 122:9196. doi:10.1016/j.eplepsyres.2016.02.014

44. Ford DE, Kamerow DB. Epidemiologic study of sleep disturbances and psychiatric disorders. An opportunity for prevention? JAMA 1989, 262(11):1479-1484. doi:10.1001/jama.262.11.1479

45. Lippman S, Gardener H, Rundek T, Seixas A, Elkind MSV, Sacco RL, Wright CB, Ramos AR. Short sleep is associated with more depressive symptoms in a multi-ethnic cohort of older adults. Sleep Medicine 2017, 40:58-62. doi:10.1016/j.sleep.2017.09.019

46. Kwan P, Yu E, Leung $H$, Leon T, Mychaskiw MA. Association of subjective anxiety, depression, and sleep disturbance with quality-of-life ratings in adults with epilepsy. Epilepsia 2009, 50(5):1059-1066. doi:10.1111/j.15281167.2008.01938.x

47. Pan CW, Cong X, Zhou HJ, Li J, Sun HP, Xu Y, Wang P. Self-reported sleep quality, duration, and health-related quality of life in older Chinese: evidence from a rural town in Suzhou, China. Journal of Clinical Sleep Medicine 2017, 13(8):967-974. doi:10.5664/jcsm.6696

48. Zhi TF, Sun XM, Li SJ, Wang QS, Cai J, Li LZ, Li YX, Xu MJ, Wang Y, Chu XF et al. Associations of sleep duration and sleep quality with life satisfaction in elderly Chinese: the mediating role of depression. Archives of Gerontology and Geriatrics 2016, 65:211-217. doi:10.1016/j.archger.2016.03.023

49. Batista BHB, Nunes ML. Evaluation of sleep habits in children with epilepsy. Epilepsy and Behavior 2007, 11(1):60-64. doi:10.1016/j.yebeh.2007.03.016

50. Stores G, Wiggs L, Campling G. Sleep disorders and their relationship to psychological disturbance in children with epilepsy. Child Care Health and Development 1998, 24(1):5-19. Child Care Health and Development

51. Biddle DJ, Hermens DF, Lallukka T, Aji M, Glozier N. Insomnia symptoms and short sleep duration predict trajectory of mental health symptoms. Sleep Medicine 2019, 54:53-61. doi:10.1016/j.sleep.2018.10.008 
Table 1 Association of insomnia symptoms and short sleep duration in the first month after the diagnosis of epilepsy with baseline participant characteristics

\begin{tabular}{|c|c|c|c|c|c|c|c|}
\hline \multirow{2}{*}{$\begin{array}{l}\text { Variables at baseline (i.e. within } 28 \text { days after } \\
\text { the diagnosis of epilepsy), unless specified }\end{array}$} & \multirow[b]{2}{*}{ Total $(n=169)$} & \multicolumn{2}{|c|}{ Insomnia symptoms } & \multirow{2}{*}{$\begin{array}{c}P \\
\text { value }\end{array}$} & \multicolumn{2}{|c|}{ Short sleep duration } & \multirow[b]{2}{*}{$P$ value } \\
\hline & & Yes $(n=33)$ & No $(n=136)$ & & Yes $(n=39)$ & No $(n=130)$ & \\
\hline \multicolumn{8}{|l|}{ Demographic and socioeconomic } \\
\hline Age, years, median (IQR), $n$ & $42(28,58), 169$ & $48(33,64), 33$ & $40(27,57), 136$ & 0.13 & $48(35,65), 39$ & $38(26,56), 130$ & 0.01 \\
\hline Male & $93(55)$ & $16(48)$ & $77(57)$ & 0.40 & $24(62)$ & $69(53)$ & 0.35 \\
\hline Married/partnereda & $92 / 164(56)$ & $16 / 32(50)$ & $76 / 132(58)$ & 0.44 & $22(56)$ & $70 / 125(56)$ & 0.96 \\
\hline Live alone & $25 / 167(15)$ & $7 / 32(22)$ & $18 / 135(13)$ & 0.22 & $7 / 38(18)$ & $18 / 129(14)$ & 0.50 \\
\hline Post-secondary education ${ }^{b}$ & $82(49)$ & $15(45)$ & $67(49)$ & 0.69 & $16(41)$ & $66(51)$ & 0.29 \\
\hline Current full/part time student & $28 / 164(17)$ & 3/32 (9) & 25/132 (19) & 0.20 & $3(8)$ & $25 / 125(20)$ & 0.07 \\
\hline Employed ${ }^{c}$ before the first seizure & $117 / 155(75)$ & $20 / 30(67)$ & $97 / 125(78)$ & 0.21 & $25 / 37(68)$ & $92 / 118(78)$ & 0.20 \\
\hline Main income earner & $80 / 149(54)$ & $14 / 28(50)$ & $66 / 121(55)$ & 0.66 & $21 / 34(62)$ & $59 / 115(51)$ & 0.28 \\
\hline Annual household income $\geq$ Aust $\$ 100,400$ & $76 / 161(47)$ & $11 / 31(35)$ & $65 / 130(50)$ & 0.15 & $13 / 38(34)$ & $63 / 123(51)$ & 0.07 \\
\hline Economic hardship ${ }^{d}$ before the diagnosis & $46 / 167(28)$ & $11(33)$ & $35 / 134(26)$ & 0.41 & $11(28)$ & $35 / 128(27)$ & 0.92 \\
\hline Private health insurance & $99(59)$ & $21(64)$ & $78(57)$ & 0.51 & $20(51)$ & $79(61)$ & 0.29 \\
\hline \multirow{2}{*}{$\begin{array}{l}\text { Own accommodation with/without mortgage } \\
\geq 2 \text { preschool or school aged children in the } \\
\text { household }\end{array}$} & $85(50)$ & $20(61)$ & $65(48)$ & 0.19 & $26(67)$ & $59(45)$ & 0.02 \\
\hline & $25 / 148(17)$ & $3 / 26(12)$ & 22/122 (18) & 0.42 & 4/32 (13) & $21 / 116(18)$ & 0.45 \\
\hline \multicolumn{8}{|l|}{ Psychosocial } \\
\hline Family function (APGAR), median (IQR), $\mathrm{n}$ & $15(13,15), 165$ & $15(13,15), 32$ & $15(13,15), 133$ & 0.88 & $15(14,15), 39$ & $15(13,15), 126$ & 0.45 \\
\hline $\begin{array}{l}\text { Risky drinking level ( } \geq 5 \text { for men, } \geq 4 \text { for women } \\
\text { on WHO-AUDIT) }\end{array}$ & $47(28)$ & $6(18)$ & $41(30)$ & 0.17 & $8(21)$ & $39(30)$ & 0.25 \\
\hline Job strain in the month before the first seizure & $25 / 115(22)$ & 2/19 (11) & 23/96 (24) & 0.19 & $6 / 24(25)$ & $19 / 91(21)$ & 0.66 \\
\hline $\begin{array}{l}\text { Treatment for mood disorders }{ }^{9} \text { before the first } \\
\text { seizure }\end{array}$ & $30 / 166(18)$ & 10/33 (30) & 20/133 (15) & 0.04 & $10 / 39(26)$ & $20 / 127$ (16) & 0.16 \\
\hline $\begin{array}{l}\text { Anxiety or depression ( } \geq 8 \text { on HADS } \\
\text { anxiety/depression subscales) }\end{array}$ & $52 / 162(32)$ & $14 / 32(44)$ & $38 / 130(29)$ & 0.12 & $17 / 38(45)$ & $35 / 124(28)$ & 0.06 \\
\hline Disability (WHODAS), median (IQR), n & $2(1,6), 168$ & $3(1,8), 33$ & $2(1,5), 135$ & 0.12 & $2(1,6), 39$ & $2(1,5), 129$ & 0.56 \\
\hline Perceived stigmah & $41 / 167(25)$ & $9(27)$ & $32 / 134(24)$ & 0.69 & $9(23)$ & $32 / 128(25)$ & 0.81 \\
\hline \multicolumn{8}{|l|}{ Clinical } \\
\hline Co-morbidityi & $61(36)$ & $18 / 33(55)$ & 43/136 (32) & 0.01 & $19(49)$ & 42/130 (32) & 0.06 \\
\hline Symptomaticj & $63(37)$ & $13(39)$ & $50(37)$ & 0.78 & $17(44)$ & $46(35)$ & 0.35 \\
\hline Generalised onset ${ }^{k}$ & $48 / 97(49)$ & $10 / 21(48)$ & $38 / 76(50)$ & 0.85 & $11 / 26(42)$ & $37 / 71(52)$ & 0.39 \\
\hline Seizure during sleep/nap & $63 / 154(41)$ & $8 / 32(25)$ & $55 / 122(45)$ & 0.04 & $14 / 34(41)$ & $49 / 120(41)$ & 0.97 \\
\hline Seizures within 2 hours after sleep/nap & $21 / 155(14)$ & $3 / 32(9)$ & $18 / 123(15)$ & 0.44 & $4 / 36(11)$ & $17 / 119(14)$ & 0.63 \\
\hline Family history of epilepsy & $30 / 165(18)$ & $6(18)$ & $24 / 132(18)$ & 1.00 & $8 / 38(21)$ & $22 / 127(17)$ & 0.60 \\
\hline
\end{tabular}




\begin{tabular}{|c|c|c|c|c|c|c|c|}
\hline \multirow{2}{*}{$\begin{array}{l}\text { Variables at baseline (i.e. within } 28 \text { days after } \\
\text { the diagnosis of epilepsy), unless specified }\end{array}$} & \multirow[b]{2}{*}{ Total $(n=169)$} & \multicolumn{2}{|c|}{ Insomnia symptoms } & \multirow{2}{*}{$\begin{array}{c}P \\
\text { value }\end{array}$} & \multicolumn{2}{|c|}{ Short sleep duration } & \multirow[b]{2}{*}{$P$ value } \\
\hline & & Yes $(n=33)$ & No $(n=136)$ & & Yes $(n=39)$ & No $(n=130)$ & \\
\hline $\begin{array}{l}\geq 8 \text { weeks for neurologist review } \\
\text { At the time of baseline assessment for the } \\
\text { following }\end{array}$ & $37 / 164(23)$ & $7 / 32(22)$ & $30 / 132(23)$ & 0.92 & $6 / 37(16)$ & $31 / 127(24)$ & 0.29 \\
\hline Taking any anti-epileptic medication & $83 / 167(50)$ & $18 / 32(56)$ & $65 / 135(48)$ & 0.41 & $20 / 38(53)$ & $63 / 129(49)$ & 0.68 \\
\hline Good adherence (taking medication regularly) & $72 / 81(89)$ & 17/18 (94) & $55 / 63(87)$ & 0.40 & $17 / 19(89)$ & $55 / 62(89)$ & 0.93 \\
\hline Carbamazepine & $24 / 167(14)$ & $3 / 32(9)$ & $21 / 135(16)$ & 0.37 & $5 / 38(13)$ & $19 / 129(15)$ & 0.81 \\
\hline Levetiracetam & 22/167 (13) & $8 / 32(25)$ & 14/135 (10) & 0.03 & $8 / 38(21)$ & $14 / 129(11)$ & 0.10 \\
\hline Valproic acid & $29 / 167$ (17) & $7 / 32(22)$ & $22 / 135$ (16) & 0.45 & $6 / 38(16)$ & $23 / 129(18)$ & 0.77 \\
\hline
\end{tabular}

Data are number of participants (percentage), or median (interquartile range, [IQR]) and number of participants. If there were missing values, the actual denominators were presented. $\mathrm{P}$ values are for the comparisons of participants with versus without insomnia symptoms and participants with versus without short sleep duration, and are in bold font when $<0.05$. Kruskal-Wallis and Chi squared tests were used for continuous and categorical variables, respectively.

Family APGAR denotes Family Adaptation, Partnership, Growth, Affection and Resolve questionnaire; WHO-AUDIT, World Health Organization`s Alcohol Use Disorders Identification Test, alcohol consumption part; HADS, Hospital Anxiety and Depression Scale; WHODAS, World Health Organization`s Disability Assessment Schedule.

aVersus no current partner (i.e. never married, widowed, divorced or separated)

Versus no formal schooling, completed primary or secondary school

${ }^{c}$ Full/part time paid employment versus retired or do not have a paid job

mortgage or rent payments, etc.) or the demonstration of dissaving behavior (i.e. borrowing or use of savings, sell assets, borrow money, etc.)

'Measured by the Job Content Questionnaire. Job strain was defined as high demands and low control

gUse of antidepressants, sleeping tablets, medication for anxiety/anxiolytics/benzodiazepine, major tranquilizers and psychotherapy

hAs a result of epilepsy, the participants think that other people are uncomfortable, treat them differently, or prefer to avoid them

includes self-reported cardiovascular, respiratory, ophthalmology, otorhinolaryngology, gastrointestinal, hepatic, renal, genito-urinary, musculoskeletal and endocrine-metabolic diseases, but not including neurological (e.g. epilepsy) and psychiatric/behavioral conditions

Symptomatic epilepsy due to encephalitis or meningitis, head injury, stroke or brain operation, versus idiopathic epilepsy

kSelf-reported, versus focal onset 
Table 2 Association of insomnia symptoms and short sleep duration course with 12-month outcomes

\begin{tabular}{|c|c|c|c|c|c|c|c|}
\hline \multicolumn{8}{|c|}{ 12-month outcomes, adjusted odds ratio ( $95 \%$ confidence interval) } \\
\hline $\begin{array}{l}\text { Pattern of } \\
\text { insomnia } \\
\text { symptoms }\end{array}$ & Model I & Model II & Model III & $\begin{array}{l}\text { Pattern of short sleep } \\
\text { duration }\end{array}$ & Model I & Model II & Model III \\
\hline \multicolumn{8}{|c|}{ Outcome 1: any seizure in the past 8 months ( 55 cases) } \\
\hline $\operatorname{Never}(n=124)$ & & & & $\operatorname{Never}(n=113)$ & & & \\
\hline Chronic $(n=19)$ & $1.42(0.49$ to 4.08$)$ & $1.29(0.43$ to 3.88$)$ & $0.78(0.23$ to 2.59$)$ & Chronic $(n=21)$ & $2.76(0.99$ to 7.71$)$ & $3.58(1.16 \text { to } 10.99)^{a}$ & $2.81(0.85$ to 9.28$)$ \\
\hline Recovery $(n=14)$ & $4.34(1.31 \text { to } 14.44)^{a}$ & 3.26 (0.97 to 10.97$)$ & $3.08(0.85$ to 11.20$)$ & Recovery $(n=18)$ & 1.35 (0.44 to 4.11$)$ & $1.29(0.39$ to 4.30$)$ & $1.22(0.34$ to 4.40$)$ \\
\hline Late $(n=12)$ & $2.95(0.85$ to 10.29$)$ & $2.87(0.77$ to 10.66$)$ & $2.18(0.56$ to 8.51$)$ & Late $(n=17)$ & 2.47 ( 0.83 to 7.37$)$ & 2.26 ( 0.73 to 6.99$)$ & $2.33(0.73$ to 7.38$)$ \\
\hline \multicolumn{8}{|c|}{ Outcome 2: anxiety or depression (40 cases) $)^{1}$} \\
\hline Never $(n=124)$ & & & & Never $(n=113)$ & & & \\
\hline Chronic $(n=19)$ & $3.92(1.37 \text { to } 11.23)^{a}$ & $3.76(1.28 \text { to } 11.06)^{a}$ & & Chronic $(n=21)$ & $5.86(2.09 \text { to } 16.37)^{\mathrm{c}}$ & $5.41(1.86 \text { to } 15.79)^{b}$ & \\
\hline Recovery $(n=14)$ & $1.37(0.35$ to 5.41$)$ & $1.03(0.25$ to 4.24$)$ & & Recovery $(n=18)$ & 1.39 (0.41 to 4.75$)$ & 1.54 (0.44 to 5.45$)$ & \\
\hline Late $(n=12)$ & $9.87(2.72 \text { to } 35.86)^{c}$ & $8.59(2.30 \text { to } 32.12)^{b}$ & & Late $(n=17)$ & $1.97(0.62$ to 6.26$)$ & $1.68(0.51$ to 5.49$)$ & \\
\hline \multicolumn{8}{|c|}{ Outcome 3: greater disability at 12 months (78 cases) } \\
\hline Never $(n=124)$ & & & & $\operatorname{Never}(n=113)$ & & & \\
\hline Chronic $(n=19)$ & $1.76(0.65$ to 4.73$)$ & $1.65(0.56$ to 4.80$)$ & $1.30(0.42$ to 4.08$)$ & Chronic $(n=21)$ & $1.84(0.70$ to 4.84$)$ & 1.70 (0.58 to 4.98$)$ & $1.57(0.51$ to 4.86$)$ \\
\hline Recovery $(n=14)$ & 0.95 (0.31 to 2.94$)$ & 0.51 (0.15 to 1.73$)$ & $0.48(0.14$ to 1.74$)$ & Recovery $(n=18)$ & $1.62(0.59$ to 4.48$)$ & 1.46 (0.48 to 4.44$)$ & $1.52(0.50$ to 4.68$)$ \\
\hline Late $(n=12)$ & $4.20(1.08 \text { to } 14.42)^{\mathrm{a}}$ & $3.62(0.84$ to 15.60$)$ & 3.11 (0.74 to 13.19$)$ & Late $(n=17)$ & 1.55 (0.55 to 4.36$)$ & 1.19 (0.41 to 3.47$)$ & 1.28 (0.42 to 3.86$)$ \\
\hline \multicolumn{8}{|c|}{ Outcome 4a: worse quality of life on EQ-5D (64 cases) } \\
\hline Never $(n=124)$ & & & & Never $(n=113)$ & & & \\
\hline Chronic $(n=19)$ & 1.88 (0.68 to 5.22$)$ & $1.70(0.56$ to 5.15$)$ & 1.31 (0.41 to 4.22$)$ & Chronic $(n=21)$ & 1.79 (0.67 to 4.78$)$ & $1.60(0.54$ to 4.72$)$ & $1.30(0.42$ to 4.07$)$ \\
\hline Recovery $(n=14)$ & 1.67 (0.53 to 5.23$)$ & $0.97(0.29$ to 3.24$)$ & $0.94(0.27$ to 3.28$)$ & Recovery $(n=18)$ & $1.22(0.42$ to 3.52$)$ & $1.28(0.40$ to 4.10$)$ & $1.20(0.37$ to 3.89$)$ \\
\hline Late $(n=12)$ & 1.96 (0.59 to 6.58$)$ & $1.42(0.38$ to 5.27$)$ & $1.13(0.29$ to 4.42$)$ & Late $(n=17)$ & $7.68(2.28 \text { to } 25.85)^{c}$ & $6.50(1.88 \text { to } 22.45)^{b}$ & $6.87(1.94 \text { to } 24.32)^{\mathrm{b}}$ \\
\hline \multicolumn{8}{|c|}{ Outcome $4 \mathrm{~b}$ : worse global rating of quality of life ( 67 cases) } \\
\hline Never $(n=124)$ & & & & Never $(n=113)$ & & & \\
\hline Chronic $(n=19)$ & $3.55(1.28 \text { to } 9.88)^{a}$ & $3.38(1.19 \text { to } 9.56)^{\mathrm{a}}$ & $3.02(1.03 \text { to } 8.84)^{\mathrm{a}}$ & Chronic $(n=21)$ & $3.11(1.16 \text { to } 8.31)^{\mathrm{a}}$ & $3.11(1.13 \text { to } 8.59)^{a}$ & $3.11(1.10 \text { to } 8.82)^{a}$ \\
\hline Recovery $(n=14)$ & $0.51(0.13$ to 1.94$)$ & 0.39 (0.10 to 1.53$)$ & 0.40 (0.10 to 1.63$)$ & Recovery $(n=18)$ & 1.30 (0.46 to 3.67$)$ & 1.41 (0.48 to 4.13$)$ & 1.44 (0.49 to 4.26$)$ \\
\hline Late $(n=12)$ & $5.75(1.46 \text { to } 22.59)^{a}$ & $5.07(1.26 \text { to } 20.43)^{a}$ & $4.65(1.15 \text { to } 18.74)^{a}$ & Late $(n=17)$ & 2.25 ( 0.80 to 6.33$)$ & $2.02(0.71$ to 5.76$)$ & $2.11(0.73$ to 6.12$)$ \\
\hline
\end{tabular}

EQ-5D denotes EuroQol Group 5-Dimension self-reported questionnaire

${ }^{1}$ To avoid overfitting of model, the minimum number of outcome events per independent variable entered into the logistic regression model is 10 . Fourty cases of anxiety of depression do not allow for Model III, where six variables need to be adjusted.

Model I is adjusted for age and sex. Model II sequentially adjusted for on/off antiepileptic medication at 12 months assessment, and presence/absence of ongoing seizures in the past 8 months at 12 months assessment (not applicable for outcome 1). Model III sequentially adjusted for history of treatment for mood disorder before the first seizure and history of co-morbidities at the diagnosis of epilepsy.

${ }^{\mathrm{a} P}<0.05 ;{ }^{\mathrm{b}} \mathrm{P}<0.01 ;{ }^{\mathrm{c}} \mathrm{P}<0.001$ 